\title{
La imagen virtual en la pintura Realista actual.
}

\author{
TIPO DE TRABAJO
}

Comunicación.

PALABRAS CLAVE

Anamorfosis Imagen Virtual Realismo Pixel.

KEY WORDS

Anamorphosis Image Virtual Realism Pixel.

\author{
RESUMEN
}

En el siglo XXI la tecnología nos sorprende, lo virtual se instala en el referente, en el modelo, propicia un cambio al igual que lo hizo la fotografía en su momento en relación con la pintura Realista. Nuevo siglo y milenio con nuevos hábitos, convenciones, y procesos creativos. Ligeras pero importantes variables aparecen en la pintura Realista. Nuestra realidad se percibe "virtualmente"; a "grosso modo" de otra manera, la importancia y la presencia de la Imagen es mayor que hace unas décadas, y el conocimiento de un mundo global a través de imágenes reflejadas en pantallas nos acompaña en todo momento, en nuestros teléfonos móviles, IPod, tablet's, Laptot's, y demás dispositivos influyendo en la concepción misma de la pintura.

Varias son las líneas de investigación aunadas en este breve estudio, todas ellas propiciadas por el uso que las Nuevas Tecnologías y la Pintura Realista hacen de la imagen simultáneamente: La anamorfosis y la perspectiva, principalmente la perspectiva cónica, usada en los sistemas de representación tradicional para interpretar y plasmar la mirada del artista se ven alteradas y modificadas en pro del único ojo de las cámaras digitales; La Pintura Realista evoluciona en algunos Géneros tradicionales que imitan y giran en torno a la fotografía digital, principalmente el Retrato; el pixel como alternativa a la pincelada dentro de la pintura Realista, y la búsqueda de una Pintura Hiperrealista High Definition (que llamare amistosamente "PHHD") alternan y conjugan paradojas, técnicas pictóricas, metáforas, programas informáticos; percepciones y sensibilidades tanto en el artista como en un espectador cada día más participe.

\section{ABSTRACT}

In the XXI century technology surprises us, what is installed on the virtual reference, in the model, provides a change like he did photography at the time regarding the Realist painting. New century and millennium with new habits, conventions, and creative processes. Slight but important variables appear in the Realist painting. Our reality is perceived "virtually"; to "roughly" otherwise, the importance and the presence of the image is larger than a few decades ago, and knowledge of a global world through images reflected in screens with us at all times, in our mobile phones, IPod, tablet's, Laptop's, and other devices influencing the conception of painting.

Several lines of research are coupled in this brief study, all prompted by the use New Technologies and Realist Painting image made simultaneously: The anamorphosis and perspective, mainly conical perspective, used in traditional systems of representation to interpret and translate the artist's eye is affected and modified one eye towards digital cameras; The Realist Painting evolves in some traditional Genres mimicking and revolve around digital photography, mainly the portrait; the pixel as an alternative to the stroke within the Realist painting, and finding a Hyperrealism Painting High Definition (I will call amicably "PHHD") alternate and combined paradoxes, painting techniques, metaphors, software; perceptions and sensitivities in both the artist as a spectator increasingly involved. 


\section{CONTENIDO}

\section{Introducción}

Real: La amplitud de acepciones y atributos que a lo largo de la historia han conformado este concepto, lo Real, la Realidad, el referente del mundo en que el artista se inspira para crear, con múltiples contenidos y técnicas pictóricas, es demasiado amplio, así pues nos centramos en lo que se refiere a pintura. Lo materico, lo palpable, lo demostrable, lo verdadero. Lo que tenemos delante, el entorno inmediato, el mundo. Lo mimético, lo medible, lo bello, etc. Todo esto conforma una amplia terminología, así pues, cito brevemente las asociaciones más aceptadas para este término dentro de la cultura Occidental. Comenzando por las definiciones que nos ofrece la R.A.E:

real. ${ }^{1}$.

(Del lat. res, rei).

1. adj. Que tiene existencia verdadera y efectiva.

realidad.

1. f. Existencia real y efectiva de algo.

2. f. Verdad, lo que ocurre verdaderamente.

3. f. Lo que es efectivo o tiene valor práctico, en contraposición con lo fantástico e ilusorio.

Estas definiciones atienden al concepto Real, mientras que la R.A.E define la imagen Real como.

\section{Imagen.}

(Del lat. imāgo, -ĭnis).

1. f. Figura, representación, semejanza y apariencia de algo.

$\sim$ real.

1. f. Ópt. Reproducción de un objeto formada por la convergencia de los rayos luminosos que, procedentes de él, atraviesan una lente o aparato óptico, y que puede ser proyectada en una pantalla.

virtual.

f. Ópt. Conjunto de los puntos aparentes de convergencia de los rayos luminosos que proceden de un objeto después de pasar por un espejo o un sistema óptico, y que, por tanto, no puede proyectarse en una pantalla.

Mientras que define lo virtual y como.

virtual.

(Del lat. virtus, fuerza, virtud).

1. adj. Que tiene virtud para producir un efecto, aunque no lo produce de presente, frecuentemente en oposición a efectivo o real.

2. adj. Implícito, tácito.

3. adj. Fís. Que tiene existencia aparente y no real.

1. f. Inform. Representación de escenas o imágenes de objetos producida por un sistema informático, que da la sensación de su existencia real.

Esta definición no nos acerca mucho al significado o los significados que se atribuyen al término virtual en la pintura, sobre todo en la figurativa y en la realista. Reflexión que ni duda tiene plantearse, pues el concepto "virtual" -al igual que el concepto "real"aplicado a la imagen, abarca históricamente un amplio abanico de definiciones que pueden llevar a confusión, y a despertar controversia. Movimientos pictóricos como el surrealismo, Realismo mágico, o simplemente las escenas pintura Histórica o Religiosa han recreado los ambientes con cierto grado de fantasía e imaginación, Invitando a la percepción de diferentes estímulos que intensifican la sensación de realidad. Frederic Chordá nos ayuda a comprender estos conceptos, y también a señalar el papel, que juega la imagen actualmente.

"Vivimos la renovación de la expresión por la Escritura, hasta hora privilegiada; otros lenguajes, alternativos, como lo visual, compiten con ella, sustituyéndola en muchos casos. Lo visual es un elemento comunicativo muy importante, capaz de soportar, en relación con otras expresiones, mejor los conceptos; por ello, el conocimiento del lenguaje visual sirve para la comprensión y articulación de mensajes. Las imágenes artísticas de todas las épocas, en su configuración, son excelentes ejemplos para ver como las ideas se expresan visualmente"

Lo Virtual tiene que ver con la posibilidad de que algo sea real en el futuro, con los mundos internos e imaginados. Esto sin duda nos lleva a reflexionar sobre el estado físico, palpable de los objetos, las cosas en tanto se les pueda atribuir ese carácter real, y continuar la reflexión refiriéndonos a la imagen contenida en los dispositivos con los que las nuevas tecnologías nos abordan y nos embaucan.

Si insisto tanto en el concepto de imagen y en su terminología es porque además de cobrar cada vez más importancia en las sociedades, ha sido, es y será el referente de la pintura y de otras expresiones y manifestaciones artísticas; activa polémica dentro de la pintura Realista en cuanto si el referente es real, y/o tomado directamente de la realidad; si es una imagen fotográfica, o si en otros casos, el referente es un arquetipo. Y si en caso de que el referente es de la fotografía, mas no de la impresa como hasta ahora se ha hecho, sino a través de la imagen que proporcionan las pantallas LCD, los sistemas informáticos.

Los entornos virtuales generados por ordenadores imitan la realidad, simulan lo reali, invitándonos a formar parte de ellos, videojuegos, mundos virtuales, salas de póker, recreaciones en el campo de la medicina, arqueología, militar...etc., estos espacios influyen más o menos dependiendo del usuario, del factor socio-económico, y de la Identidad y la cultura, principalmente. Gracias a 
la Interfaz, y las cartografías en la red, el conocimiento de la pintura se convierte en asequible para los artistas y usuarios, y por tanto las influencias de otros artistas son mayores, conectando la obra más afín.iii
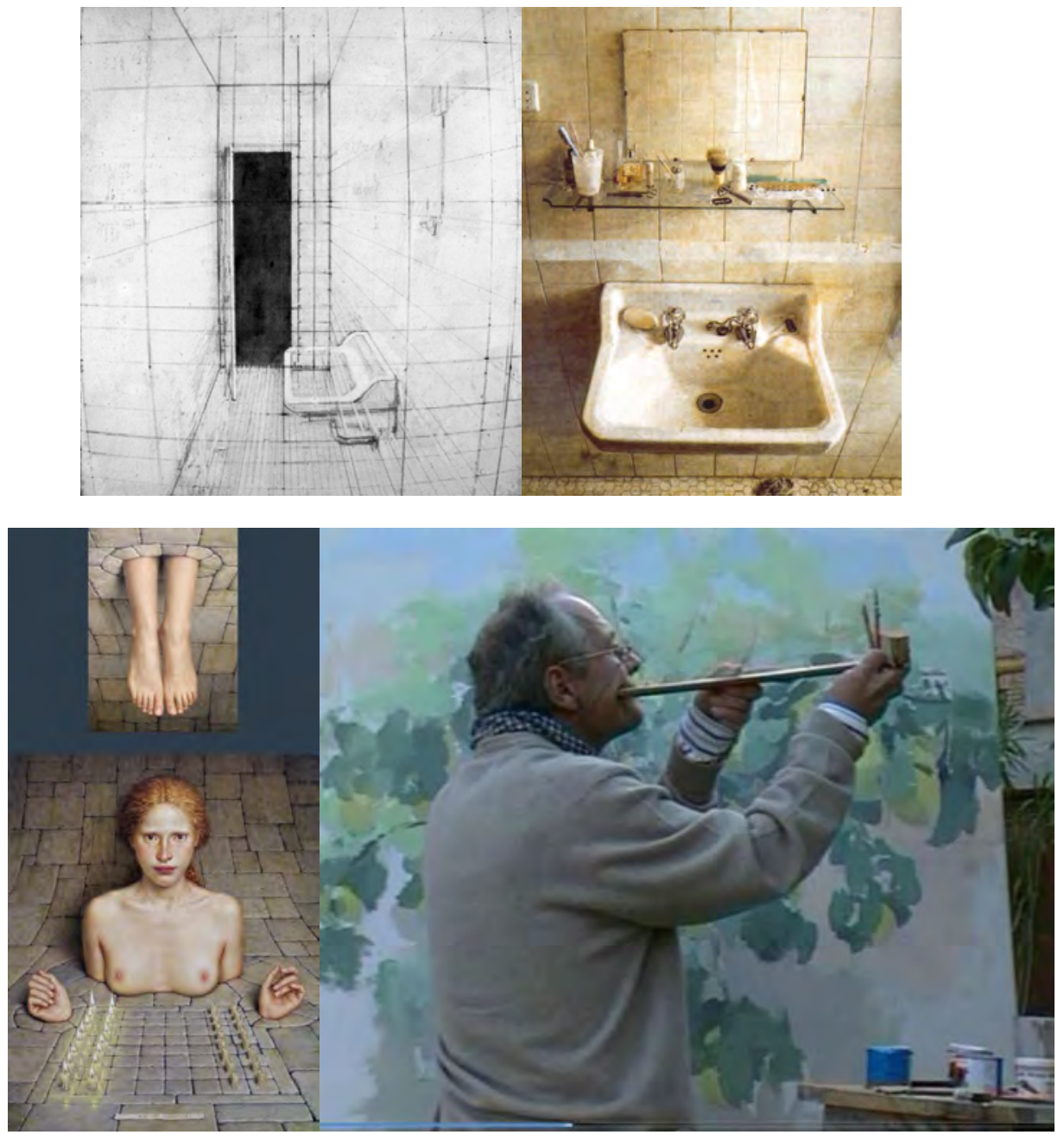

\title{
(De Izqda. a dcha.; de arriba a abajo) \\ Antonio López García. Cuarto de baño. 1971 iv \\ Antonio López García. Lavabo y espejo. 1967" \\ Dino Valls. Ut Superius. Óleo / lienzo. Díptico: $100 \times 50 \mathrm{~cm} .2003^{v i}$ \\ Antonio López García: Medicion con escuadra y compas ${ }^{\text {vii }}$
}

\begin{abstract}
"nada es verdad ni es mentira, todo es según el color, del cristal con que se mira" "viii. Los dispositivos electrónicos conducen nuestra mirada en los hogares, en las aulas, y sobre todo los dispositivos móviles, como celulares, laptot's, IPod, Smartphone, que nos proporcionan imágenes a través de una pantalla, cuyos parámetros en cuanto a color y perspectiva están alterados por los sistemas informáticos de percepción de la imagen. Cada vez más la pintura Realista toma como referente estas imágenes que se almacenan en el momento, instantes del entorno más cercano, el que tenemos a mano sin concebir ni esperar fenómeno ni acontecimiento, se diferencian de la mirada del ser humano en varios aspectos importantes. De esta manera la pintura Realista experimenta un trayecto hacia lo virtual a través del referente; se apoya en una imagen que ya no proviene del objeto en sí, de la naturaleza que se nos muestra delante, sino que ha sido creada por medios informáticos. La dimensión espacio-temporal cambia Lo que Antonio López llama la vivencia, el aura impresa en el "plain-air", se sustituye por la "inmersión" en las imágenes de las pantallas que se alejan de la mirada del ser humano.
\end{abstract}

Una sola lente frente al sistema bifocal natural de las personas.

El Angulo de visión y la visión panorámica se alteran dependiendo del dispositivo.

La calidad de la imagen aumenta en cuanto a la resolución de la imagen.

La luminosidad y espectro de color también cambian a través del pixel. 
La tecnologías denominadas L.C.D (liquid crystal display) ${ }^{i x}$ y $O L E D^{x}$ en distintos formatos de pantalla nos proporcionan, guardan y modifican imágenes que sustituyen nuestra mirada ${ }^{\mathrm{xi}}$. Cambia el mundo, cambia el referente, empezamos a hablar de virtualidad, de no-realidad. La pintura alberga lo Virtual y lo Real; la calidad de la imagen que el pintor en este caso imita, deriva a menudo hacia el hiperrealismo.

Imaginamos entrar en las imágenes, en un espacio diferente, condicionados en parte por un ángulo de visión más amplio que el del ojo humano. ¿Hasta dónde ha influido la fotografía en nuestra percepción visual de la realidad? Lo que nos dicen sus cuadros es que "vemos fotográficamente"

La trayectoria de nuestra mirada se acota, se educa, se habitúa; los principios de la perspectiva quedan condicionados, de modo ajeno al espectador; ya no es natural, no es la zona "0", la mancha ciega aiii entre la córnea y la fóvea la que determina los parámetros de esta anamorfosis, sino la puntual y concreta definición de la trayectoria que incluye la programación y fabricación de las pantallas LCD y otras tecnologías, de sus filtros y sensores. La pintura Realista corrige la trayectoria de la perspectiva con una angulación modificada por medio de artilugios como la ballestilla en el caso del pintor Antonio López García.

El ángulo de visión de las pantallas LCD: 160 vertical x 170은 horizontal.

Las pantallas de plasma que pueden ser vistas desde cualquier ángulo, siempre y cuando el ángulo de visión es de entre 160 a a 180 .

La diferencia visual, reside como ya hemos dicho en estos cambios ópticos, pero también en el contenido, en los códigos que utiliza el artista y que nos transmiten conocimiento, se consolida el paisaje urbano y una simbología generada normalmente en las ciudades.

"Ia figuración de los noventa proporciona una nueva temática que procura, entre otras muchas cosas, pintar la vida moderna, la arquitectura, el objeto industrial, las edificaciones, las ciudades, los personajes aislados, los suburbios industriales, el alma de los propios objetos ${ }^{\prime \prime x i v}$

La voluntad humana de generar espacios virtuales, cuyos antecedentes son el teatro griego y la cámara oscura ${ }^{\mathrm{xv}}$ según Josep $\mathrm{M}$ Catalá, se acentúa con las nuevas tecnologías, este cambio de referente va acompañado del peligro de limitar, de reemplazar nuestra capacidad imaginativa. Lo que F. Chordá denomina como "línea franca" ${ }^{\text {”vi }}$ de la nueva era, cuyas posibilidades de interactuación, difusión y virtualidad, serpentean en estructuras variables e ilimitadas.

\section{EL RETRATO Y EL SELFY: DEL REFLEJO DEL ALMA A LA IMAGEN MEDIÁTICA}

Otra vez simulacro y apariencia aparecen, también en el género del retrato. El alma del retratado, su presencia real y verdadera, el peso de su mirada, se sustituye por la precisión técnica en la Pintura, y una imagen creada normalmente por el retratado, muy distinta del tradicional autorretrato, más bien como un avatar, para mostrar ante la sociedad. El selfy, proporciona una imagen virtual del modelo; lo suplanta en una representación teatral característica de una época donde lo global y lo virtual están muy presentes gracias a la imagen, y que también nos plantea un carácter más efímero y sustitutivo del Retrato
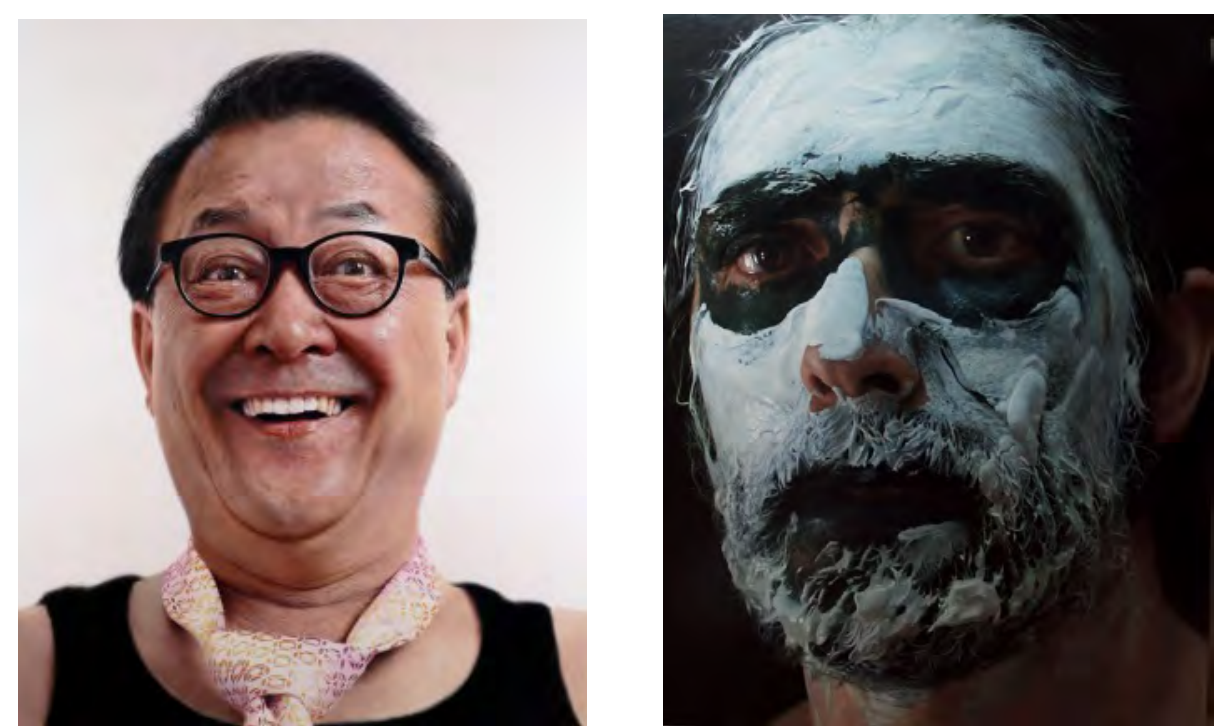

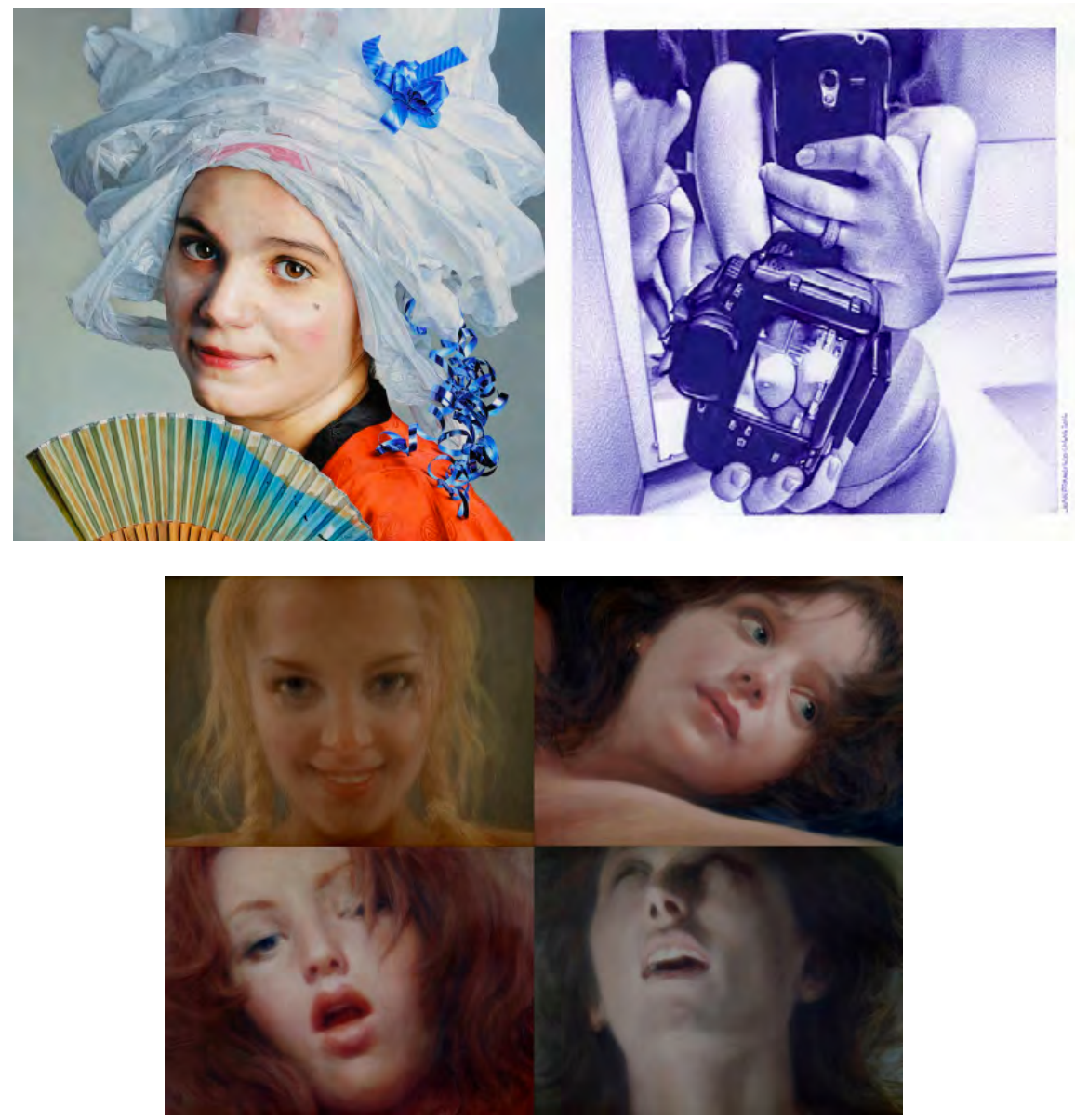

(De Izqda. a dcha.; de arriba a abajo) ${ }^{\text {xii }}$

Kang Kang Hoon. Boy-n moderna comedia aceite sobre lienzo. 193,9 × 130.3cm. 2009.

Eloy Morales. Autorretrato.

José Luis Corella "Lady Plastic"

Juan francisco casas Ruiz (bolígrafo)

Luis García Mozos. "Webcams 1", óleo sobre papel imprimado y encolado sobre tablex, 50x70 cm

Ampliando el concepto de Realidad, la pintura Realista no solamente refleja un cambio en la composición o la técnica, sino también en la temática, los contenidos son otros obviamente. Nuevos hábitos sociales se perpetúan en la pintura Realista, como el selfy o las imágenes propias de las webcam que navegan en las redes sociales.

\section{EL PIXEL COMO PARTE INTEGRAL DE LA PINTURA}

Podemos encontrar analogías con el efecto de pixelado en la en los mosaicos romanos, el puntillismo también puede ser un referente. En la actualidad, la división geométrica en pequeñas unidades que contrastadas recrean la forma, ya es algo convencionalizado en la imagen digital. Las celdillas que componen las pantallas LCD contienen gases como argón o xenón son excitadas mediante electricidad, creando los pixeles. Esto explicado de maneta sencilla nos permite una idea de que la resolución de la imagen, medida en pixeles, depende de la cantidad de estas celdas, sensores y filtros de color, y de los pixeles que recrean. Desde que el Realista Chuck Close, debido a la dificultad de percibir los rostros debido a una enfermedad denominada prosopagnosia diseccionara los retratos en pequeños apartados o celdas, de un modo similar a como se nos presenta la imagen pixelada, la tecnología busca una simbiosis conceptual con la pintura.

"El pintor explicó que divide cada cuadro en centenares, a veces miles, de unidades o celdillas a las que da un mínimo de tres pinceladas. El paralelismo con los píxeles es evidente dado que un píxel (PIcture x ELement) es la unidad básica de una imagen digital. En efecto, uno de los muchos méritos del artista es que inventó esas celdillas antes de saber qué era un píxel; quizás antes de que los píxeles existieran ${ }^{\prime \prime x i x}$ 

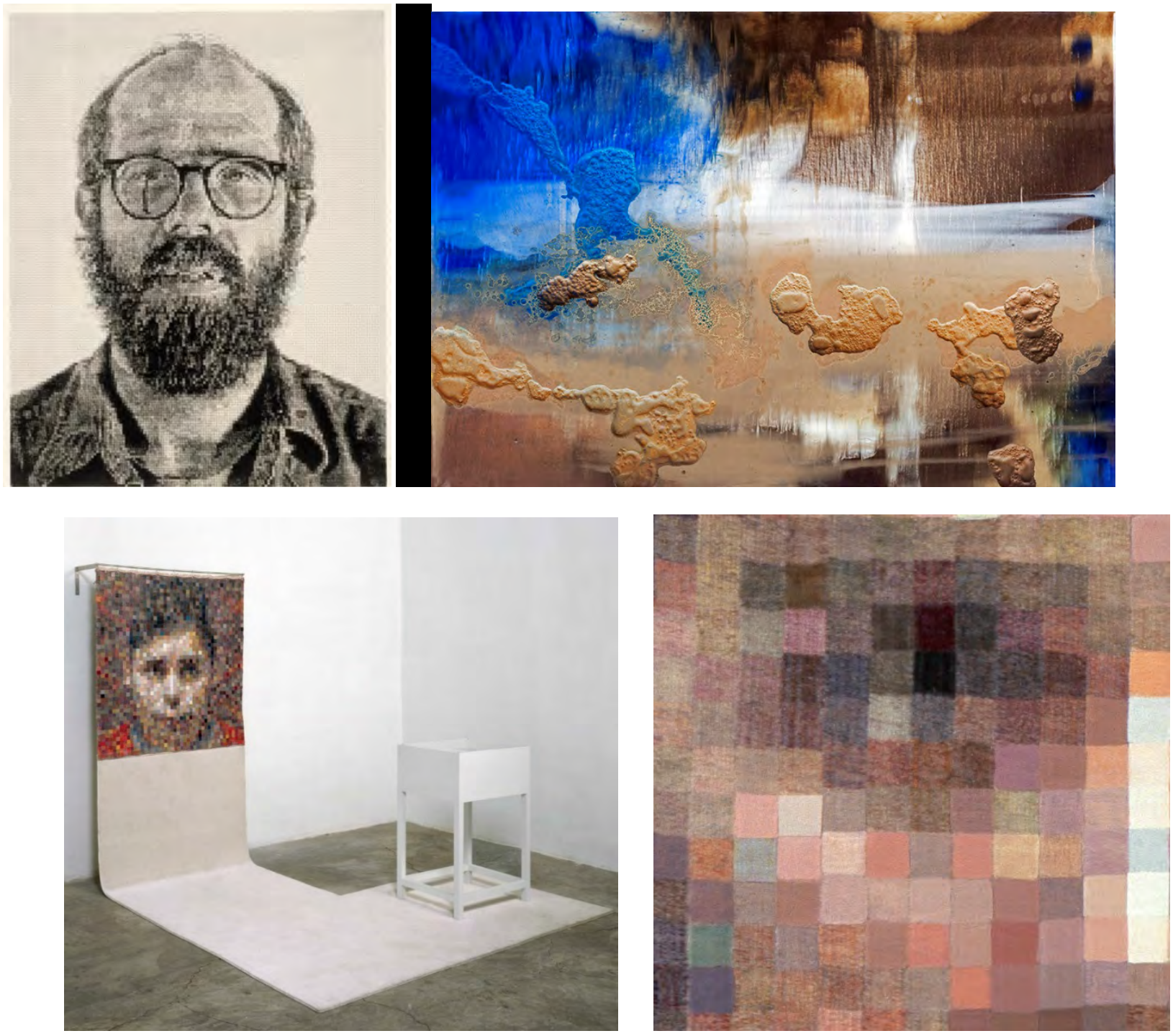

Chuck Close. Autorretrato de 1977. Aguafuerte sobre papel. 112 x $89 \mathrm{~cm}$. Darío Urzay, Flip, 2015, técnica mixta.

Yishai Jusidman, muestra de la exposición Mutatis Mutandis.

Continuamos con un planteamiento pictórico que se aleja del realismo y se centra directamente en el pixel. El artista mexicano Yishai Jusidman, inicia su andadura artística como aprendiz de Carlos Orozco Romero en el periodo de 1973 a 1980, desde entonces investiga la imagen y la pintura. En el año 2000 presenta en el Centro de la Imagen de Ciudad de México la exposición Mutatis Mutandis, que después viajara a Sao Paulo, Paris, Oaxaca, Venecia y Monterey, en la cual sitúa el uso del pixel dentro de la obra pictórica. La gran cantidad de imágenes que nos proporcionan los mass-media, y que pueden crear confusión, establecen relaciones que contraponen dentro de la pintura, lo táctil y lo visual, lo fenoménico y lo discursivo.

\section{PINTURA HIPERREALISTA EN ALTA DEFINICIÓN “PHHD”}

Dentro del Hiperrealismo más reciente, en España y fuera de ella, sobre todo en Norteamérica, y países como Japón, cuya tradición pictórica se asemeja a nuestra pintura en la representación mimética, la influencia de la imagen digital con alta resolución -RAW ${ }^{\mathrm{xx}}$ - y la ausencia del índex y la háptica, en una pintura aparentemente sin carga materica, propician cambios como el mayor uso del Acrílico, en consonancia con el color de la imágenes digitales, y el mayor uso de la óptica en el proceso de creación Pictórica.

Un caso digno de mención el de la pintura de Darío Urzay, que imita mediante la fotografía digital, la carga materico de la pintura. La amplitud de lo posible, la voluntad del artista y la necesidad cognitiva de representación Realista se recogen en una pintura con un lenguaje propio, imágenes impresas en soporte de aluminio que transgreden los límites del espacio bidimensional del soporte representando la carga materica a través del pixel. 


\section{CONCLUSIONES}

La pintura Realista actual apuesta por la representación mimética y una mayor precisión técnica, buscando un lenguaje visual cuya difusión y comprensión se distribuye "ipso facto" en redes sociales y espacios virtuales, mostrando como la sociedad y las nuevas tecnologías condicionan el referente que oscila entre lo Real y lo Virtual.

\section{CITAS}

"Ya no me pasaba desapercibida la vida diaria, la concentración extrema y obsesiva en el hecho pictórico que provoca que todos los mecanismos perceptivos y conceptuales estén desplegados en un estado de alerta permanente; la disección extrema de lo que nos rodea. Empecé a comprender que la emoción podría encontrarse en la luz, en los objetos, en las paredes, en los rostros o en las flores. Es decir, el mundo entero podía estar en lo más próximo (...) la llave que nos abre estas puertas es el tiempo, y también la capacidad de sentir y de creer. Por eso ahora veo la obra de mi padre siempre en presente y siempre cambiante. Es el tiempo presente su verdadero motor y lo que le mueve a transformar y revisar tantas veces una misma obra"

"Lo que priva es la teatralidad. Para el visitante culto, la habilidad de la reconstrucción; para el ingenuo, la violencia de la información: hay para todos. ¿De que lamentarse? La información histórica desemboca en lo sensacional; lo verdadero se mezcla con lo legendario;...(...)...pero la obra maestra de la preocupación reconstructiva (y de dar el máximo y lo mejor) se encuentra cuando esta industria de lo icónico absoluto aborda el problema del arte" ${ }^{\prime x x i i}$

"por la voluntad de perfeccionamiento cada vez mayor de su función mimética, por la exaltación de la capacidad extensiva de la imagen como copia fidelísima de las apariencias ópticas del mundo visible, es una ambición que culmina en el hiperrealismo de la realidad virtual”"xxiii

BIBLIOGRAFIA.

Dibujo Técnico 3. Bachillerato. Martínez Arturo, Bernal Jesús. Ed: SM. ISBN: 84-348-0177-9. Madrid 1978.

Serrano León, David. Metodología Pictórica en la Obra de Antonio López García. Pictorical Methodology in Antonio López Work. Editado por la Universidad de Murcia.

SERRANO LEÓN, David. "La importancia de la precisión geométrica en la obra de Antonio López García". Revista: Bellas Artes. Revista de Artes Plásticas, Estética, Diseño e Imagen. Vol. 10. Las Palmas de Gran Canaria: Universidad de La Laguna, 2012 (noviembre). 22páginas. ISSN: 1695-761X

SERRANO LEÓN, David, “Metodología pictórica en la obra de Antonio López García”, Revista: Laboratorio de Arte. Vol. 24, Sevilla: Universidad de Sevilla, 2012, pp. 717-737. ISSN: 1130-5762

Alcolea Blanch, Santiago (s.alcolea@amatller.com) Aníbal, máscaras y anamorfosis en el Cuaderno italiano de Goya. Instituto Amatller de Arte Hispánico Barcelona, 1998.

Chorda, Frederic. "De lo visible a lo virtual. Una metodología del análisis artístico" Ed: Antrophos. 2004. Rubí (Barcelona) ISBN: 847658-690-6. DI: b-37-059-2004 p.:9. Introduccion

Gubern, Román. Del bisonte a la Realidad Virtual. La escena y el laberinto. Ed. Anagrama. Barcelona 1996. ISBN. 84/339/0534/1. Dep. Legal. 39315/1999

Marchan, Simón. Real/Virtual en la estética y la teoría de las artes. Ed. Paidós Ibérica 2006. Barcelona. ISBN. 84/493/1827/0. Dep. Legal. B.44.067/2005.

Catálogo de la exposición "Hiperrealismo 1967 - 2012" en el Museo Thyssen-Bornemisza. Edición inglesa publicadas por Hatje Cantz Verlag 2013. Edición española publicada por la Fundación Colección Thyssen-Bornemisza. ISBN: 978-84-15113-38-36

Eco, Umberto. La Estrategia de la Ilusión. Traducción de Edgardo Oviedo. Editorial lumen. Titulo original: semiología cotidiana. Publicado por editorial lumen, S.A. tercera edición 1999. DP.- B. \&.530-1999. ISBN.- 84-264-1164-9. 
Catálogo de la Exposición realizada por Felisa Martínez Andrés. La huella fotográfica en la nueva pintura realista. La aportación valenciana (1963-2005). Centre del Carme Octubre 2009-Enero 2010. Generalitat Valenciana.

Catalá Domenech, Josep. M. La imagen compleja. La fenomenología de las imágenes en la era de la cultura visual. Ed: Universitat Autónoma de Barcelona. Servei de publicacions. 08193 Bellaterra (Barcelona) ISBN.- 84-490-2397-1

Bozal, Valeriano. Mimesis: las imágenes y las cosas. Visor distribuciones. Ediciones Antonio Machado 1987. Madrid. ISBN: 84-7774003-8. Dep. Legal: M.35.632-1987.

Azara, Pedro. El ojo y la sombra. Una mirada al retrato en Occidente. Ed: Gustavo Gili, S. A. Barcelona, 2002. ISBN: 84-252-1903-5. Dep. Legal B. 22.796-2002.

Valls, Dino. Ex picturis II. Works from 2002-2014. Ed: Galerie Vevais 2014. ISBN: 978-3-936165-28-9

Valls, Dino. Metaphysician of beauty and pain. Ed: Galerie Vevais 2014. ISBN: 978-3-936165-28-9

Valls, Dino. Ex Picturis. La pintura de Dino Valls. Edward Lucie Smith. Mira Editores, Zaragoza 2001. ISBN: 84-8465-046-4.

www.dinovalls.com

www.eloymorales.es

www.yishaijusidman.com/es

www.dariourzay.com

http://www.museoreinasofia.es/exposiciones/chuk-close-pinturas-1968-2006

www.joseluiscorella.com

www.juanfranciscocasas.com

theartofluisgarciamozos.blogspot.com

kangkanghoon.com

antoniolopezgarcia.blogspot.com

\footnotetext{
Chorda, Frederic. "De lo visible a lo virtual. Una metodología del análisis artístico" Ed: Antrophos. 2004. Rubí (Barcelona) ISBN: 84ii "invertir el platonismo significa entonces: mostrar los simulacros, afirmar sus derechos entre los iconos las copias... (...)...El simulacro no es una copia degradada; oculta una potencia positiva que niega el original, la copia, el modelo y la reproducción. La simulación (...) es el funcionamiento del simulacro en cuanto maquinaria, maquina dionisiaca" G. Deleuze "la lógica del sentido" En: Marchan, Simón. Real/Virtual en la estética y la teoría de las artes. Ed.Paidos Ibérica 2006. Barcelona. p. 44.

iii La interfaz, tiene sus antecedentes en el teatro griego, como espacio donde el público se ve inmerso en lo visual y lo auditivo, y en la cámara oscura, en la que el espectador entra en un espacio donde la imagen del mundo lo sobrecoge al ser independiente de él. La televisión ya no mostraba la imagen del mundo sino con otra realidad escondida detrás de ella. La necesidad de mirar, de desentrañar la realidad da paso a la metáfora, a la construcción de la mirada, fundamentando la interfaz como espacio virtual en el que se aúnan las operaciones del usuario y el ordenador, usando el lenguaje realista, un lenguaje mimético capaz de despertar emoción y subjetividad. Los lenguajes matemáticos, algorítmicos que la interfaz emplea también se reflejan en la pintura, en la siempre activa preocupación humana por expresarse y reflejar el entorno, la Realidad se forja con imágenes virtuales.

iv Este cuadro del pintor Antonio Lopez Garcia muestra la metodologia que permite corregir la percepcion natural de la perspecttiva.

${ }^{\vee}$ El efecto optico que invita a introducirse en el espacio de la pintura, se consigue aplicando distintas perspectivas, puntos de vista en la misma imagen.

vi Esta obra del pintor Dino Valls, aplica tambien distintos puntos de vista llevandonos a mundos virtuales creados a partir de arquetipos propios del artista.

vii Antonio Lopez, ajustando los parametros del natural, teniendo en cuenta los cambios que se producen en el referente, dia tras dia, mediante escuadra y compas.
} 


\begin{abstract}
viii Hace más de dos siglos que Ramón de Campoamor (Asturias 1817) escribe esta estrofa que nos recuerda que ningún valor es inmutable, dentro de lo relativo nuestras habilidades perceptivas están ahorita condicionadas por la tecnología.

ix Una pantalla de cristal líquido o LCD (sigla del inglés liquid crystal display) es una pantalla delgada y plana formada por un número de píxeles en color o monocromos colocados delante de una fuente de luz o reflectora. A menudo se utiliza en dispositivos electrónicos de pilas, ya que utiliza cantidades muy pequeñas de energía eléctrica.
\end{abstract}

${ }^{x}$ las pantallas OLED tienen un funcionamiento mucho más sencillo. En este tipo de tecnología los diodos emisores de luz orgánicos sí que funcionan como píxeles y/o subpixeles independientes que crean una imagen. Algo asi como las pantallas hechas de bombillas que se pueden ver en muchos espectáculos.

${ }^{x i}$ nuestra visión es capaz de abarcar casi los 180 grados en el plano horizontal, y algo menos en el plano vertical. Esto, en teoría, significaría que nuestro ojo podría equivaler a una longitud focal entre los 9 y los $13 \mathrm{~mm}$. Pero también hay que asumir que de esos $180^{\circ}$ sólo somos capaces de enfocar una mínima parte.

xii Catálogo de la exposición HIPERREALISMO 1967-2012. MUSEO THYSSEN -BORNEMISZA. Edición a cargo de Otto Lete. Textos de Linda Chase, Nina S. Knoll, Otto Lezte, Louis K. Meisel y Uwe M. Sheneede. Patronato de la Fundación Colección Thyssen-Bornemisza. p.: 21.

xiii El centro de la retina, llamado fóvea, dirige la dirección de la mirada, afinando la apreciación de la realidad. Esto cambia con la visión lateral, la llamada mancha ciega, carente de células visuales, se establece en una zona elíptica correspondiente a la fijación del nervio óptico sobre la retina; de esta manera la psique rellena el hueco. La visión es un fenómeno esencialmente psíquico, que de manera inconsciente en un sistema de visión binocular como es el humano nos lleva a percibir las rectas corrigiendo su curvatura.

${ }^{\text {xiv }}$ En el Catálogo de la Exposición realizada por Felisa Martínez Andrés. La huella fotográfica en la nueva pintura realista. La aportación valenciana (1963-2005). Centre del Carme Octubre 2009-Enero 2010. Generalitat Valenciana. p.: 54

${ }^{x v}$ El teatro griego como espacio que envuelve al espectador con lo auditivo y lo visual, y la cámara oscura -modelo creado por Athanasius Kircher- donde el espectador entra literalmente, percibiendo la realidad a través de imágenes que se generan de forma ajena e independiente a él. "divorcio entre sujeto y objeto, distinción trascendental entre la mirada artística y la visión científica: una regida por las emociones, la otra por la razón” En: Catalá Domenech, Josep. M. La imagen compleja. La fenomenología de las imágenes en la era de la cultura visual. Ed: Universitat Autonoma de Barcelona. Servei de publicacions. 08193 Bellaterra (Barcelona) pp.: $537-540$.

${ }^{x v i}$ En: Chorda, Frederic. "De lo visible a lo virtual. Una metodología del análisis artístico" Ed: Antrophos. 2004. Rubí (Barcelona) p.: 185

xvii Las diferentes pinturas que aquí aparecen retratan las nuevas concepciones del autorretrato, de la identidad en una sociedad que se comunica a través de la imagen.

xviii El término prosopagnosia deriva del griego prosopon que significa "cara" y agnosia que es la "ausencia de conocimiento" y coloquialmente se define como un problema para reconocer caras. El termino fue acuñado por el médico J. Bodamer en 1947, quien describió dos casos de esta singular alteración perceptiva y la definió como "la interrupción selectiva de la percepción de rostros, tanto del propio como del de los demás, los que pueden ser vistos pero no reconocidos como los que son propios de determinada persona". http://www.neurorhb.com

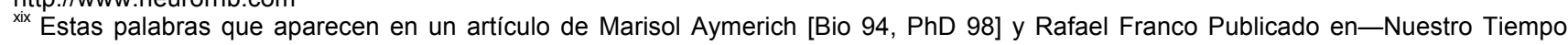
abril-junio 2013 p: 32 "Chuck Close y los rostros perdidos" (Marisol Aymerich y Rafael Franco son investigadores de Bioquímica y Biología Molecular del CIMA Neurociencias) nos aclaran que es lo que pixel sustituye en la pintura, y cuál es su prodiga presencia, siendo su imagen "habitual" en al arte actual.

${ }_{x x}$ Formato de imagen original de alta resolucion es un formato de archivo digital de imágenes que contiene la totalidad de los datos de la imagen tal y como ha sido captada por el sensor digital de la cámara fotográfica.

xxi En: "Antonio López" Art: "sobre mi padre" María López Moreno .Catalogo de la exposición del Museo Thyssen Bornemisza. 28 de junio-25 de septiembre de 2011, p.: 30-31

xxii En: Eco, Umberto. La Estrategia de la Ilusión. Traducción de Edgardo Oviedo. Editorial lumen. Titulo original: semiología cotidiana. Publicado por editorial lumen, S.A. tercera edición 1999 p.: 25.

xxiii En: Gubern, Roman. Del bisonte a la Realidad Virtual.La escena y el laberinto.Ed. Anagrama. Barcelona 1996 p.: 8 